Original Article

\title{
The effect of non-elastic taping on balance and gait function in patients with stroke
}

\author{
Chan-Woo Nam, PT, MS ${ }^{1)}$, Jung-Ho Lee, PT, PhD²), Sung-Hyoun Cho, PT, $\mathrm{PhD}^{3)^{*}}$ \\ 1) Department of Physical Therapy, College of Rehabilitation Science, Daegu University, Republic of \\ Korea \\ 2) Department of Physical Therapy, Kyungdong University, Republic of Korea \\ 3) Department of Physical Therapy, Nambu University: 23 Chumdan, Gwansangu, Gwangju 506-706, \\ Republic of Korea
}

\begin{abstract}
Purpose] This study investigated the influence of exercise on balance ability and gait function in stroke patients after applying non-elastic tape, which can stabilize muscles and joints, to the lower extremities of the affected side. [Subjects and Methods] The subjects were 30 patients diagnosed with stroke. They were divided into an experimental group $(n=15)$ and a control group $(n=15)$. The experimental group performed mat and treadmill exercises three times a week for six weeks with non-elastic tape applied to the lower extremities of the affected side. The control group performed the same exercises but without taping. [Results] The intervention significantly improved Berg balance scale scores and timed up and go (TUG) test scores as well as reduced stance duration and stride duration in the experimental group. In the control group, statistically significant improvements were observed in TUG test scores. [Conclusion] Although some differences did not reach the level of statistical significance, the application of non-elastic tape stabilized the joints of the lower extremities, thereby increasing balance and reducing stance duration and one step duration, which resulted in a reduction of overall gait duration.
\end{abstract}

Key words: Stroke, Non-elastic taping, Balance

(This article was submitted May 11, 2015, and was accepted Jun. 9, 2015)

\section{INTRODUCTION}

Stroke is a disease that occurs when the blood supply in the brain is interrupted by a hemorrhage or infarction, resulting in movement and consciousness disorders. A stroke can occur at any age, although two-thirds of patients are over 60 years old ${ }^{1)}$.

The main symptoms include not only physical impairment, such as hemiplegia and sensory loss, but also impaired cognition, visual deficit, verbal deficit, and social problems. These complications can limit mobility, which results in decrease of activities of daily living $(\mathrm{ADL})^{2}$. It has been reported in previous studies that stroke patients experience problems with motor control, voluntary movements, and posture maintenance, limiting the effectiveness of their movements ${ }^{3)}$

In the early phase of stroke, the symptoms described above tend to be mild or temporary. However, permanent disability can develop in severe cases, and psychological depression can accompany the compromised physical function ${ }^{4)}$. Stroke is the most common neurological disease in the world and

*Corresponding author. Sung-Hyoun Cho (E-mail: geriatricpt1@naver.com)

C2015 The Society of Physical Therapy Science. Published by IPEC Inc. This is an open-access article distributed under the terms of the Creative Commons Attribution Non-Commercial No Derivatives (by-ncnd) License $<$ http://creativecommons.org/licenses/by-nc-nd/3.0/> . the main cause of movement disorders ${ }^{5}$. Although normal gait patterns have been described in stroke patients, they are impaired in the majority of cases ${ }^{6}$. The limitations are usually confined to one side, dividing the body into affected unaffected sides. The unaffected side of the body bears more weight, whereas the affected side carries less load ${ }^{7}$.

Furthermore, the asymmetric postural arrangement of the trunk and lower extremities in hemiplegic patients reduces the stability of the trunk and proximal part of the lower extremities ${ }^{8}$, altering normal and natural gait patterns as well as the symmetric balance of the body ${ }^{9}$. Thus, during walking, $30-40 \%$ of the overall body weight of a stroke patient is shifted to the affected side. This can cause instability of posture control and reduce mobility and balance ability ${ }^{10)}$.

Weight shifting exercises for the affected side are necessary for restoring the normal range of movement and muscle strength, which facilitates the movements of the unaffected lower extremities by providing the required stability ${ }^{11)}$. The purpose of this study was to investigate the balance ability and gait function in stroke patients after applying non-elastic tape to the lower extremities of the affected side, which can stabilize muscles and joints.

\section{SUBJECTS AND METHODS}

In this study, stroke patients were randomly assigned to two groups after their general characteristics were determined. Fifteen subjects in the experimental group performed mat and treadmill exercises three times a week for six weeks 
with non-elastic tape applied to the lower extremities of the affected side. Subjects in the control group performed the same exercises without taping. The participants were provided with a written informed consent form in accordance with the ethical standards of the Declaration of Helsinki.

The exercise program consisted of mat exercise and treadmill exercise. In the mat exercise, the trunk was fixed and correctly arranged to start the exercise in the supine position. A therapist then stretched the ankle and knee joints of the patient, and active-assistive flexion/extension exercise of the lower extremities was performed for 10 minutes. In addition, sit-to-stand exercise, which induced pelvic movement, was also performed for 10 minutes in each session.

Gait exercise was performed using a treadmill after applying non-elastic tape. The subjects started the treadmill exercise at the lowest speed $(1 \mathrm{~km} / \mathrm{h})$, and the speed was slowly increased according to the patient's ability. The exercise was performed for 20 minutes three times a week for six weeks. A 2- or 3-minute break was provided after each exercise session.

Non-elastic tape was applied according to the method of $\mathrm{Kim}^{12)}$. Five $\mathrm{cm}$-wide tape was applied after measuring the distance from the tibial tuberosity to the inferior anterior iliac spine (IAIS). One end of the tape was attached to the IAIS, and the other end was divided in two and placed directly on the patella. The divided ends were then attached to the tibial tuberosity in line with the edge of the knee with the hip extended and the knee flexed.

The Berg balance scale (BBS) was used to assess dynamic balance ability in this study. This tool, which consists of 14 items, is used in clinical practice to assess balance in ambulation and when standing in hemiplegic patients. Corresponding measurements have good validity and reliability, as the intra-rater and inter-rater reliability were found to be 0.99 and 0.98 , respectively ${ }^{13)}$.

The timed up and go (TUG) test, which is used to assess mobility and gait, was performed from a sitting position on a chair.

Time required to perform the task was recorded three times, and the average value was calculated. It has been previously reported that healthy adults perform the task within 10 seconds, whereas frail elderly subjects accomplish it within 11-20 seconds. A time exceeding 20 seconds indicates functional motor impairment and increased risk of falling. This measurement tool is known to be reliable and valid, with an inter-rater and intra-rater reliability of 0.98 and 0.99 , respectively ${ }^{14)}$.

In this study, the Dartfish software was also used for gait analysis after the gait of subjects was recorded with a video system. Spatio-temporal analysis is widely used to evaluate the gait pattern of hemiplegic patients, and the temporal component can improve clinical significance ${ }^{15)}$. The video recording was conducted in the sagittal plane twice during a 5-m walk after the greater trochanter, lateral epicondyle, lateral malleolus, and metatarsophalangeal joint of the 5th toe were marked with a sticker ${ }^{16)}$.

The results were presented as means \pm SD. SPSS for Windows 20.0 was used for statistical analysis. The $\chi^{2}$ test and the independent $t$-test were used to investigate the general characteristics of the subjects. The paired t-test was used to
Table 1. General characteristics of the subjects (mean $\pm \mathrm{SD}$ )

\begin{tabular}{lcc}
\hline & $\begin{array}{c}\text { Experimental group } \\
(\mathrm{n}=15)\end{array}$ & $\begin{array}{c}\text { Control group } \\
(\mathrm{n}=15)\end{array}$ \\
\hline Age (years) & $64.4 \pm 10.9$ & $65.3 \pm 5.8$ \\
Weight $(\mathrm{kg})$ & $60.0 \pm 10.7$ & $62.8 \pm 6.7$ \\
Height $(\mathrm{cm})$ & $159.3 \pm 9.0$ & $163.6 \pm 8.0$ \\
History (month) & $24.2 \pm 11.3$ & $28.2 \pm 11.6$ \\
Gender $(\mathrm{M} / \mathrm{F})$ & $7 / 8$ & $9 / 6$ \\
\hline
\end{tabular}

compare the characteristics before and after the intervention in each group, and the independent t-test was employed to compare differences between the groups. The significance level was set at 0.05 .

\section{RESULTS}

There were no significant differences in the general characteristics between the experimental and control groups $(\mathrm{p}>$ 0.05) (Table 1).

In the experimental group, there were significant changes in all parameters except for swing duration. Although there was a statistically significant change in the TUG scores in the control group, the other parameters showed no differences. Only the BBS and TUG scores differed significantly between the groups (Table 2, 3).

\section{DISCUSSION}

This study investigated the influence of non-elastic taping on clinical balance ability and gait function, especially with respect to gait speed, in patients with stroke. Generally, stroke patients show decreased motor function accompanied with sensory deficit, causing difficulties with posture control and maintenance ${ }^{17}$.

The decreased motor function not only reduces the quality of life (QOL) and affects ADL, but also leads to the loss of independence, low self-esteem, and depression ${ }^{18)}$. Furthermore, cognitive impairment also reduces independence and ability to participate in social activities, diminishing the QOL ${ }^{19}$.

In addition, compromised postural control, decreased joint mobility, impaired proprioception, and muscle weakness reduce the ability to maintain balance, and this abnormal balance negatively influences ADL and gait pattern, increasing the risk of secondary injury, for example, caused by falls ${ }^{20)}$

The reduced balance hinders recovery of $\mathrm{ADL}$ and motor functions as well as interferes with regaining independent gait by inducing sensory deficit ${ }^{21}$ and antagonism of contraction and relaxation in the lower extremities of patients $^{22)}$. Moreover, it has been reported that two-thirds of stoke patients suffer from reduced mobility accompanied with gait impairment ${ }^{23}$. Thus, the ability to control balance is an important component required for performing $\mathrm{ADL}$, and restoration of balance control is a fundamental goal of rehabilitation of stroke patients ${ }^{24)}$.

Taping, which stabilizes muscles and joints, is widely 
Table 2. Comparison of BBS and TUG scores between the experimental and control groups (mean $\pm \mathrm{SD}$ )

\begin{tabular}{|c|c|c|c|c|c|}
\hline & \multicolumn{2}{|c|}{ Experimental group } & & \multicolumn{2}{|c|}{ Control group } \\
\hline & $\begin{array}{c}\text { Pre-test } \\
(\mathrm{n}=15)\end{array}$ & $\begin{array}{c}\text { Post-test } \\
(\mathrm{n}=15)\end{array}$ & & $\begin{array}{l}\text { Pre-test } \\
(\mathrm{n}=15)\end{array}$ & $\begin{array}{c}\text { Post-test } \\
(\mathrm{n}=15)\end{array}$ \\
\hline BBS (score)* & $34.1 \pm 4.1$ & $38.6 \pm 3.0$ & BBS (score) & $35.9 \pm 3.6$ & $37.6 \pm 4.6$ \\
\hline TUG (score)* & $36.3 \pm 14.3$ & $34.6 \pm 14.1$ & TUG (score)* & $36.9 \pm 11.1$ & $34.4 \pm 10.2$ \\
\hline Stance duration (s)* & $1.2 \pm 0.6$ & $0.9 \pm 0.1$ & Stance duration(s) & $1.3 \pm 1.0$ & $1.1 \pm 0.2$ \\
\hline Swing duration (s) & $0.5 \pm 0.1$ & $0.5 \pm 0.1$ & Swing duration(s) & $0.5 \pm 0.1$ & $0.4 \pm 0.0$ \\
\hline Stride duration $(\mathrm{s})^{*}$ & $1.8 \pm 07$ & $1.4 \pm 0.2$ & Stride duration(s) & $1.8 \pm 0.9$ & $1.5 \pm 0.3$ \\
\hline
\end{tabular}

$* \mathrm{p}<0.05$, BBS: Berg balance scale, TUG: timed up and go test

Table 3. Comparison of the improvements in the experimental and control groups (mean $\pm \mathrm{SD})$

\begin{tabular}{lcc}
\hline & $\begin{array}{c}\text { Experimental group } \\
(\mathrm{n}=15)\end{array}$ & $\begin{array}{c}\text { Control group } \\
(\mathrm{n}=15)\end{array}$ \\
\hline BBS (score)* & $-4.5 \pm 3.0$ & $-1.6 \pm 3.2$ \\
TUG (score)* & $1.6 \pm 0.8$ & $2.5 \pm 1.5$ \\
Stance duration(s) & $0.3 \pm 0.4$ & $0.2 \pm 1.0$ \\
Swing duration(s) & $0.0 \pm 0.1$ & $0.0 \pm 0.1$ \\
Stride duration(sec) & $0.3 \pm 0.5$ & $0.2 \pm 0.9$ \\
\hline
\end{tabular}

$*_{p}<0.05$, BBS: Berg balance scale, TUG: timed up and go test

used to correct muscle imbalance and unstable posture, thus improving balance control. Taping also prevents secondary injury of joints and muscles as well as reduces treatment duration by compensating the skin and ligaments ${ }^{25}$.

Taping treatment stimulates muscle spindles and Golgi tendon organs, which increases transverse muscle area. It has also been reported that fine pressure directed from the skin to muscles affects muscle spindles and Golgi tendon organs, leading to tendon muscle relaxation, muscle strengthening, and pain relief ${ }^{26)}$. The ultimate purpose of the taping treatment is to support and protect joints by limiting their movement and compensating for the function of ligaments, which is necessary for effective functional movement ${ }^{27}$. Kilbreath et al. ${ }^{28)}$ reported that taping had a positive effect on gait speed and distance of gait cycle via improving hip extension during stance phase in stroke patients. A previous study has also shown that taping of the hip abductor stimulated its activation and increased gait speed in hemiplegic stroke patients using a cane. In another study, 14 women with patellofemoral pain showed increased activation of the vastus medialis after taping of the patella ${ }^{29}$.

The purpose of this study was to investigate the effect of taping during mat and treadmill exercises on balance and gait function. Balance was assessed using the BBS, which has good reliability and validity. Significant changes in balance were observed in the experimental group after the exercises. In addition, the Dartfish software was used to analyze video recordings of moving subjects. Significant changes in TUG scores after the exercises were observed in both groups. Stance duration and one step duration were significantly reduced in the experimental group. Although a similar tendency was also present in the control group, the corresponding differences were not statistically significant. Significant differences between the groups were observed only in TUG scores.

These results suggest that non-elastic taping affects balance and gait function in stroke patients. However, prolonged taping should be avoided and the tape should be removed immediately after completing the exercise in patients with skin diseases or if excessive pressure is present. Clinical relevance of the present findings needs to be examined in future research. Limitations of this study include a small number of subjects and short duration. Accordingly, long-term effects of taping are currently unknown, and generalizability of the conclusions needs to be investigated.

In conclusion, although some differences were not statistically significant, the application of non-elastic tape increases joint stability of the lower extremities, thereby improving balance and reducing stance duration and one step duration, which results in the reduction of overall gait duration.

\section{REFERENCES}

1) Park SG, Hyun JK, Lee SJ, et al.: Quantitative evaluation of very acute stage of complex regional pain syndrome after stroke using three-phase bone scintigraphy. Nucl Med Commun, 2007, 28: 766-770. [Medline] [CrossRef]

2) Wolfe CD, Taub NA, Woodrow EJ, et al.: Assessment of scales of disability and handicap for stroke patients. Stroke, 1991, 22: 1242-1244. [Medline] [CrossRef]

3) Jaraczewska E, Long C: Kinesio taping in stroke: improving functional use of the upper extremity in hemiplegia. Top Stroke Rehabil, 2006, 13: 31-42. [Medline] [CrossRef]

4) Kleindorfer D, Judd S, Howard VJ, et al.: Self-reported stroke symptoms without a prior diagnosis of stroke or transient ischemic attack: a powerful new risk factor for stroke. Stroke, 2011, 42: 3122-3126. [Medline] [CrossRef]

5) Lopez $\mathrm{AD}$, Mathers $\mathrm{CD}$ : Measuring the global burden of disease and epidemiological transitions: 2002-2030. Ann Trop Med Parasitol, 2006, 100: 481-499. [Medline] [CrossRef]

6) Jørgensen HS, Nakayama H, Raaschou HO, et al.: Recovery of walking function in stroke patients: the Copenhagen Stroke Study. Arch Phys Med Rehabil, 1995, 76: 27-32. [Medline] [CrossRef]

7) Bobath B: Adult hemiplegia: evaluation and treatment, 3rd ed. London: Heinemann Medical, 1990.

8) Chen G, Patten C, Kothari DH, et al.: Gait differences between individuals with post-stroke hemiparesis and non-disabled controls at matched speeds. Gait Posture, 2005, 22: 51-56. [Medline] [CrossRef]

9) Lane RE: Facilitation of weight transference in the stroke patient. Physiotherapy, 1978, 64: 260-264. [Medline]

10) Horstman AM, Beltman MJ, Gerrits $\mathrm{KH}$, et al.: Intrinsic muscle strength and voluntary activation of both lower limbs and functional performance after stroke. Clin Physiol Funct Imaging, 2008, 28: 251-261. [Medline] [CrossRef]

11) Shumway-Cook A, Anson D, Haller S: Postural sway biofeedback: its ef- 
fect on reestablishing stance stability in hemiplegic patients. Arch Phys Med Rehabil, 1988, 69: 395-400. [Medline]

12) Kim DY, Seo BD: Immediate effect of quadriceps Kinesio taping on the anaerobic muscle power and anaerobic threshold of healthy college students. J Phys Ther Sci, 2012, 24: 919-923. [CrossRef]

13) Blum L, Korner-Bitensky N: Usefulness of the Berg Balance Scale in stroke rehabilitation: a systematic review. Phys Ther, 2008, 88: 559-566. [Medline] [CrossRef]

14) Podsiadlo D, Richardson S: The timed "Up \& Go": a test of basic functional mobility for frail elderly persons. J Am Geriatr Soc, 1991, 39: 142-148. [Medline] [CrossRef]

15) Roth EJ, Merbitz C, Mroczek K, et al.: Hemiplegic gait. Relationship between walking speed and other temporal parameters. Am J Phys Med Rehabil, 1997, 76: 128-133. [Medline] [CrossRef]

16) Eltoukhy M, Asfour $S$, Thompson $C$, et al.: Evaluation of the performance of digital video analysis of human motion: Dartfish Tracking System. IJSER, 2012, 3: 1-6.

17) Geurts AC, de Haart M, van Nes IJ, et al.: A review of standing balance recovery from stroke. Gait Posture, 2005, 22: 267-281. [Medline] [CrossRef]

18) Giaquinto $S$, Giachetti I, Spiridigliozzi C, et al.: Quality of life after stroke in a rehabilitation setting. Clin Exp Hypertens, 2010, 32: 426-430. [Medline] [CrossRef]

19) Verhoeven CL, Post MW, Schiemanck SK, et al.: Is cognitive functioning 1 year poststroke related to quality of life domain? J Stroke Cerebrovasc Dis, 2011, 20: 450-458. [Medline] [CrossRef]

20) Tyson SF, Hanley M, Chillala J, et al.: The relationship between balance, disability, and recovery after stroke: predictive validity of the Brunel Bal- ance Assessment. Neurorehabil Neural Repair, 2007, 21: 341-346. [Medline] [CrossRef]

21) Tyson SF, Hanley M, Chillala J, et al.: Balance disability after stroke. Phys Ther, 2006, 86: 30-38. [Medline]

22) Patterson KK, Gage WH, Brooks D, et al.: Evaluation of gait symmetry after stroke: a comparison of current methods and recommendations for standardization. Gait Posture, 2010, 31: 241-246. [Medline] [CrossRef]

23) Hsu AL, Tang PF, Jan MH: Analysis of impairments influencing gait velocity and asymmetry of hemiplegic patients after mild to moderate stroke. Arch Phys Med Rehabil, 2003, 84: 1185-1193. [Medline] [CrossRef]

24) Walker C, Brouwer BJ, Culham EG: Use of visual feedback in retraining balance following acute stroke. Phys Ther, 2000, 80: 886-895. [Medline]

25) Mohammadi HK, Pouretezad M, Shokri E, et al.: The effect of forearm kinesio taping on hand grip strength of healthy people. J Kerman Uni Med Sci, 2010, 17: 248-256.

26) Wilson LR, Gandevia SC, Inglis JT, et al.: Muscle spindle activity in the affected upper limb after a unilateral stroke. Brain, 1999, 122: 2079-2088. [Medline] [CrossRef]

27) McCaw ST, Cerullo JF: Prophylactic ankle stabilizers affect ankle joint kinematics during drop landings. Med Sci Sports Exerc, 1999, 31: 702-707. [Medline] [CrossRef]

28) Kilbreath SL, Perkins S, Crosbie J, et al.: Gluteal taping improves hip extension during stance phase of walking following stroke. Aust J Physiother, 2006, 52: 53-56. [Medline] [CrossRef]

29) Gilleard W, McConnell J, Parsons D: The effect of patellar taping on the onset of vastus medialis obliquus and vastus lateralis muscle activity in persons with patellofemoral pain. Phys Ther, 1998, 78: 25-32. [Medline] 